\title{
Hacia una literatura de disidencia sexual en México con dos Bildungsromane bisexuales: Púrpura, de Ana García Bergua, y Fruta verde, de Enrique Serna
}

\author{
Brandon Patrick Bisbey \\ Northeastern Illinois University
}

Resumen

En este artículo propongo una lectura de las novelas mexicanas Púrpura, de Ana García Bergua, y Fruta verde, de Enrique Serna, como representaciones de la bisexualidad que se insertan en, y a la vez rompen con, una tradición literaria que retrata la homosexualidad masculina. Leo el empleo de la ironía y el performance de género en los textos como señalamiento de las contradicciones y dificultades sociales que conllevan la orientación bisexual. El diálogo de las obras con la tradición de la novela de formación problematiza la expresión de sexualidades no normativas y plantea una crítica de las identidades sexuales basadas en el binarismo hetero / homosexual. Sostengo que estas obras deben ser incluidas en y analizadas dentro de la tradición literaria mexicana que retrata sexualidades disidentes, entre las cuales la bisexualidad ha sido una identidad marginada.

Palabras clave: bisexualidad, Bildungsroman, género, performance, posmodernidad.

\section{Abstract}

In this article I propose a reading of the Mexican novels Púrpura by Ana Garcia Bergua and Fruta verde by Enrique Serna as portrayals of bisexuality that both form a part of and break with a literary tradition that portrays male homosexuality. I read the use of irony and 
gender performance in these texts as a signaling of the social contradictions and problems that come with the bisexual orientation. The dialogue of these works with the tradition of the novel of formation problematizes the expression of non-normative sexualities and critiques sexual identities based on the heter/homo binary. I argue that these works should be included in a Mexican literary tradition that represents dissident sexualities, among which bisexuality has been marginalized and underrepresented.

Keywords: bisexuality, Bildungsroman, gender, performance, postmodernity.

\section{Introducción}

Dirpura (1999), de Ana García Bergua, y Fruta verde (2006),
de Enrique Serna, son dos obras que se insertan en una dición literaria que identifico como "literatura de disidencia sexual mexicana". Con esto me refiero a toda obra literaria publicada originalmente en México, o por autor de origen mexicano, que represente sexualidades disidentes y que pueda ser incluida entre las prácticas culturales de la disidencia sexual de este país. ${ }^{1}$ Siguiendo a Héctor M. Salinas Hernández, entiendo la disidencia sexual como el "conjunto de identidades, acciones sociales y políticas de sujetos politizados, y el ejercicio cotidiano de prácticas sexuales no politizadas, que no son reconocidas como legítimas por la institución heterosexual" (2010: 28). La definición de Salinas abarca distintas nociones de identidad, de actividad política y de prácticas culturales. Esta última esfera se compone de dos elementos: la subcultura gay y las prácticas culturales que se alejan tanto de las normas heterosexuales como de las normas de la subcultura gay

\footnotetext{
${ }^{1}$ Así, incluiría literatura de temática homosexual, lésbica, gay, bisexual, travesti, transgénero y de cualquier otra sexualidad disidente.
} 
(33). Es aquí donde la noción de una orientación bisexual podría ser productiva, como descriptor de prácticas sexuales que no caben dentro de una concepción binaria de la orientación sexual (heterosexual / homosexual).

Salinas nota que la bisexualidad es actualmente una identidad marginada entre los movimientos de disidencia sexual en México, en parte porque muchos grupos políticos de gays y de lesbianas no la aceptan como auténtica (328). Paralela a la marginalización política de la identidad, existe una relativa escasez de representaciones literarias de la orientación bisexual en México en comparación con las representaciones de la homosexualidad masculina. Debido a la presencia de tales representaciones en la literatura, es posible hablar de una corriente novelística de temática homosexual o gay en la literatura mexicana contemporánea. ${ }^{2}$ Sostengo que Púrpura y Fruta verde comparten con esta tradición una preocupación central con la disidencia sexual y un enfoque en las prácticas homosexuales entre hombres, pero que se distinguen por su representación de la bisexualidad. Mientras que la mayoría de los protagonistas de las novelas de temática homosexual o gay son identificados como homosexuales o gays, en Púrpua y Fruta verde los personajes no son identificados así. De hecho, éstos eluden o rechazan la elección de una identidad basada en la orientación sexual mientras mantienen relaciones sexuales tanto con hombres como con mujeres. Por eso, argumento que estas novelas deben ser incluidas dentro de la literatura de disidencia sexual como representaciones de la bisexualidad masculina.

${ }^{2}$ Esta tradición incluiría obras como El diario de José Toledo (1964), de Miguel Barbachano Ponce; 41, de Paolo Po (1964); El vampiro de la colonia Roma (1979), Melodrama (1983) y La historia de siempre (2007), de Luis Zapata; Las púberes canéforas (1983) y Mátame y verás (1994), de José Joaquín Blanco; Utopía gay, de José Rafael Calva (1985), entre otros. 
El apoyo de la lectura de los protagonistas de estas novelas como bisexuales depende de tres puntos: la representación literaria de su orientación sexual a través de sus prácticas y expresiones de atracción sexual; su performance ambiguo de género, que resalta su relación con la cultura heterosexual y con la subcultura homosexual o gay; y la relación irónica y paródica de las novelas con el género decimonónico del Bildungsroman, que presenta una visión posmoderna de la adaptación social de los protagonistas. Tomando estos tres elementos en conjunto, podemos leer las novelas como críticas de las identidades sexuales basadas en una concepción binaria de la orientación sexual (heterosexual / homosexual). No obstante el cuestionamiento de la identidad sexual presente en los dos textos, sostengo que la bisexualidad es el concepto que mejor describe la orientación sexual de los personajes, y que es importante incorporar estos textos a la literatura de disidencia sexual en México como novelas que representan la bisexualidad masculina.

\section{Dos protagonistas bisexuales}

De la misma manera que la homosexualidad y la heterosexualidad, el concepto de la bisexualidad tiene sus raíces en los discursos científicos de los siglos XIX y XX; de ahí que todavía se use para referirse tanto a la atracción sexual a, y prácticas sexuales con, personas de ambos sexos. A partir de la década de 1970 también se empieza a usar como una identidad de disidencia sexual (Beemyn, 2004). ${ }^{3}$ En su exhaustivo estudio Bisexuality and the Eroticism of Everyday Life, Marjorie Garber sugiere que las últimas décadas del siglo XX se da el auge de una bisexual chic (moda bisexual) en Occidente, evidenciada por la presencia de temas relacionados con

${ }^{3}$ Esta identidad está presente en la más común representación actual de la coalición de identidades basadas en la diversidad sexual, el movimiento Lésbico Gay Bisexual Trans Queer (LGBTQ). 
la bisexualidad en la cultura popular (películas, televisión, figuras como David Bowie y Madonna, etc.) y un aumento en la adopción de la identidad bisexual (1995: 16-25). En México ha habido un pequeño aumento de producción cultural reciente que trata de la bisexualidad masculina, como la película de Alfonso Cuarón, $Y$ tu mamá también (2001), en la que los personajes Tenoch y Julio ${ }^{4}$ encarnan una impaciente sexualidad adolescente, y la novela Cuerpo náufrago (2005), de Ana Clavel, en la que un personaje femenino despierta un día convertido en un hombre cuya sexualidad desborda los papeles tradicionales hetero y homosexuales. ${ }^{5}$

A los márgenes de los discursos científicos modernos, las sexualidades en América Latina no son fieles reproducciones de los comportamientos norteamericanos y europeos, sino que evidencian diferencias esenciales que problematizan las categorías de taxonomía sexual. Por eso es importante, al estudiar representaciones literarias de sexualidades latinoamericanas, tener presente tanto las semejanzas como las diferencias con sexualidades norteamericanas y europeas. Sobre todo es importante evitar el exotismo y el encasillamiento de los comportamientos e identidades de personas en América Latina. ${ }^{6}$ Aun teniendo en cuenta estos peligros, sostengo que la bisexualidad es un concepto productivo para hablar de la orientación sexual de los protagonistas de Púrpura y Fruta verde. El primer indicio que posibilita una lectura de los personajes como bisexuales viene de su caracterización, ya que evidencian atracción

${ }^{4}$ Representados por los actores Diego Luna y Gael García Bernal, respectivamente.

${ }^{5}$ La novela de Clavel no está incluida en este estudio porque no dialoga tan directamente con el género del Bildungsroman como las novelas analizadas aquí. ${ }^{6}$ Un problema de este tipo, señalado por Robert M. Irwin, ha sido la tendencia de algunos estudiosos y activistas de Estados Unidos de asumir que la homosexualidad mexicana es una versión subdesarrollada o premoderna de la homosexualidad norteamericana (2000: 128). 
hacia ambos sexos y sus prácticas sexuales incluyen tanto a hombres como a mujeres.

Púrpura es una novela narrada en primera persona por un tal Artemio González, quien rememora una serie de eventos de su juventud que lo llevaron a varios descubrimientos importantes: su vocación artística, la hipocresía de la oligarquía mexicana y su orientación sexual. La acción tiene lugar mayormente en una ciudad ficticia que evoca el México de los ańos treinta y cuarenta sin fijar un momento preciso. En el empleo de su exitoso primo Mauro, Artemio viaja de la provincia a la capital, intentando "progresar" según su entendimiento informado por la literatura francesa decimonónica. La atracción sexual y las relaciones amorosas son una parte íntegra de su proceso de formación, y los objetos de tales atenciones fluctúan a lo largo de la novela. Al comienzo de su narración, Artemio es rechazado por la secretaria de la fábrica donde trabaja como oficinista. Al llegar a la casa de Mauro, la atracción que siente hacia éste se hace evidente, comunicada oblicua e irónicamente por la voz narrativa: "Y eso que sus ojos azules eran de lo más bonito que yo había visto, sin ser maricón, pero es que deveras, ni las muchachas más lindas que conocía y que me gustaban mucho, ni Pura la secretaria de la fábrica tenía esos ojos" (García Bergua, 1999: 16).

Esta incipiente atracción es una fuente de angustia para Artemio, quien pronto descubre que Mauro y su amigo Lizárraga en verdad son pareja. Rumbo a la capital para cumplir con mandatos de su primo, Artemio se fija en Alejandra Ledesma, "una señorita ya algo jamona", la vista de cuyos senos le permite asegurarse que es todo un hombre, a quien le gustan más las mujeres que su primo (24-27). Alejandra resulta ser pianista y miembro de la alta sociedad capitalina, y Artemio la elige como el blanco de sus atenciones, llegando eventualmente a acostarse con ella. Antes de este encuentro, sin embargo, se había acostado con Freddy Santamaría, 
un decorador de cine contratado para adornar la casa que Mauro ocupará en la capital por una temporada. Durante su estadía en la capital Artemio no sólo se acuesta con Freddy y Alejandra, sino que también sucumbe a los encantos de Lola, una joven prostituta, y empieza una ambigua amistad con tonos homoeróticos con un joven actor llamado Ramón. Al final de la narración, Artemio ha logrado besar a Mauro en la boca, pero los primos nunca llegan a tener relaciones sexuales. Las últimas páginas de la novela dejan claro que Artemio se ha mudado a Hollywood, donde trabaja como guionista y comparte su cama con Lola y Ramón, quienes trabajan como actores. Varios críticos han visto en estos comportamientos una homosexualidad latente, mientras otros han identificado a Artemio como un personaje homosexual o gay. ${ }^{7}$ Sin embargo, yo argumentaría que la escena que cierra la novela, tomada en conjunto con su comportamiento sexual a lo largo la novela, refleja una orientación bisexual.

Fruta verde es una novela ambientada en la Ciudad de México de finales de los ańos setenta que relata un importante periodo formativo en la vida de Germán Recillas, un joven escritor en ciernes. Al ingresar a la universidad y el mundo laboral, Germán empieza a diferenciarse de su madre Paula y llega a formar una intensa relación intelectual, emotiva y sexual con un hombre mayor, el dramaturgo Mauro Llamas. ${ }^{8}$ Éste intenta seducir al joven desde su primer encuentro, y gran parte de la tensión narrativa de Fruta verde se centra en la gradual aceptación de Germán de su atracción hacia Mauro. Desde un principio vacila entre el rechazo y la fascinación con la cultura de Mauro y los otros colegas gays en la agencia de publicidad donde trabajan. La primera tarde que conoce a Mauro teme estar "perdiendo el miedo a la jotería”, pero se asegura inmediatamente después que "[n]adie se ha vuelto ma-

${ }^{7}$ Cfr. Cázares, 2001; Domínguez Michael, 1999; Gil, 2007; y Thornton, 2010a. ${ }^{8}$ Parece que la repetición del nombre en las dos obras es mera coincidencia. 
ricón por hacer un poco de travestismo mental" (Serna, 2006: 79). A partir de ahí la convivencia entre los dos, que el joven llega a ver como una especie de educación cultural superior a la universidad, se caracteriza por el acercamiento emocional y la paulatina cesión de Germán a los avances de Mauro, quien compara al joven con "[...] esas criadas rejegas que al ir por el pan, esquivan a manotazos los toqueteos del novio, rezongando con voz queda: 'Estate sosiego, Lencho'” (161). Esto es, Mauro considera los rechazos débiles de Germán como una ambivalencia que realmente lo invita a continuar con la seducción.

La observación burlona de Mauro parece estar basada en cierta verdad, ya que finalmente Germán se acuesta con él y mantienen una relación amorosa por unos meses. Sin embargo, un nuevo conflicto se establece entre los dos - la negativa de Germán de asumirse como gay y de dejar de interesarse por las mujeres-. Unas entradas en el diario de Germán, que están intercaladas en la narración, expresan su reticencia a renunciar a cualquier de los dos mundos a los que pertenece, el mundo gay de Mauro y el heterosexual de su familia: "¿Pero estoy seguro de ser un joto hecho y derecho? ¿Qué pasa si al poco tiempo me enamoro de una mujer en calidad de lesbiana?” (264). Teme que nadie lo aceptará tal como es. Aunque el personaje no se refiere a su orientación sexual como bisexualidad, la clara expresión de la atracción hacia ambos sexos es mejor calificado con ese término.

Fruta verde termina con una especie de coda en la que el Germán actual se presenta como el autor de la historia narrada anteriormente. Después de su relación con Mauro, Germán se casa con una mujer, tiene una hija, se vuelve novelista exitoso, se divorcia, y sobrevive a su madre y a Mauro, con quien ha mantenido una gran amistad. En el funeral de Mauro, Germán es llamado a hacer las veces de viuda, lo cual implica un reconocimiento público de su calidad de ex-amante. Debido a esta escena, y al reconocimiento 
de Serna de la base autobiográfica de la novela, ${ }^{9}$ se ha leído el texto como una narrativa de salida del clóset bisexual que problematiza la narrativa confesional. ${ }^{10}$ Queda claro, pues, después de una consideración de la caracterización de Germán, que la bisexualidad puede describir su orientación sexual.

\section{El papel del performance de género}

En estas dos novelas hay una estrecha relación planteada entre la orientación sexual y el género. Tanto en Púrpura como en Fruta verde, de hecho, los protagonistas exhiben un performance ambiguo de género que apoya la lectura de ellos como personajes bisexuales. Se trata de una alternación entre comportamientos masculinos asociados con la heterosexualidad y comportamientos femeninos que sugieren la homosexualidad. Según Carlos Monsiváis, en el imaginario popular mexicano predomina una imagen del hombre homosexual como afeminado, la cual cristalizó con el caso de los 41 hombres arrestados en una fiesta de travestidos en la Ciudad de México en 1901: "Desde entonces y hasta fechas recientes en la cultura popular el gay es el travesti y sólo hay una especie de homosexual: el afeminado" (1995: 199). El estereotipo del hombre homosexual que actúa como mujer es empleado en son de burla en la cultura popular mexicana, desde los grabados de los 41 hombres de José Guadalupe Posada hasta las telenovelas recientes, y es un indicio de la marginalización de las sexualidades disidentes. Por otro lado, este mismo escarnio ha sido apropiado por la cultura de disidencia sexual en México, y la adopción de una feminidad exagerada se ha vuelto parte importante del sentido de humor gay

${ }^{9}$ Serna ha dicho que la relación entre Germán y Mauro está basada en su relación con el difunto dramaturgo mexicano Carlos Olmos. Cfr. García Hernández, 2006 e "Irreverencia...", 2006.

${ }^{10}$ Cfr. Thornton, 2010b. 
mexicano. Como argumenta José Joaquín Blanco en su famoso ensayo "Ojos que da pánico sońar", este sentido de humor es un arma importante frente a la discriminación y un valor compartido de una comunidad (1979: 189-190).

Esta relación entre la actuación femenina y la orientación sexual puede ser entendida con referencia a la noción de la performatividad del género avanzada por Judith Butler. Para Butler, el género no es equivalente al sexo, sino una construcción social que es formada a través de una reiterada serie de actuaciones o actos performativos. No es una esencia preexistente, sino una apariencia y una identidad construida que es formada por la repetición de ciertos movimientos corporales. Dada esta naturaleza performativa, el género no obedece las leyes de la naturaleza sino las normas de la sociedad. De ahí que el género pueda ser representado en maneras que no siguen las normas sociales asociadas con él (1988: 520). ${ }^{11}$ Empleando la terminología de Butler es posible hablar de una asociación entre el performance del género femenino por los hombres y la homosexualidad en México. En Púrpura y Fruta verde los personajes principales evidencian un performance vacilante que oscila entre lo masculino y lo femenino que resalta su carácter bisexual.

En Púrpura la performatividad del género es explotada en varias referencias irónicas hechas por el narrador sobre la orientación sexual de su yo más joven. Así es que después de estar con Freddy Santamaría, Artemio habla de haber dejado en la cama su "doncellez masculina", double entendre que juega con la noción de perder la virginidad y la masculinidad a la vez (120). Al hacer el amor con Freddy algunas veces más, Artemio es atacado por

${ }^{11}$ Aunque hay una implicación en la teoría de Butler de que el performance nonormativo del género puede llegar a hacer más evidente la naturaleza arbitraria y construida del género, y así tener un efecto liberador en la sociedad, Butler no argumenta que el performance sea necesariamente siempre subversivo o liberador. 
la culpa y los deslices homosexuales de su pensamiento diario le preocupan. Durante la decoración de la casa de su primo en México, el protagonista duerme en una covacha del jardín y fantasea con que Alejandra llegue a hacerle el amor como en El amante de Lady Chatterley, de D. H. Lawrence. Después, la covacha es ocupada por un joven y atractivo jardinero cuya presencia inquieta a Artemio: "No pude evitar, al ver al muchacho que se acercaba, de sonrisa franca y juvenil, pensar en la escena a la lady Chatterley que había concebido yo alguna vez con Alejandra cuando habitaba la covacha, pero ahora era al revés: si acaso quien debía encarnar a lady Chatterley era yo" (127). Mientras comentarios como este establecen un nexo claro entre el performance de la feminidad y la homosexualidad, muchas las acciones de Artemio son ambiguas en términos de género.

Niamh Thornton ha notado en el comportamiento de Artemio el performance de una feminidad melodramática — se ruboriza, se desmaya, habla en términos cursis sobre el amor (2010a: 228). Aunque es cierto que muchos de sus comportamientos pueden ser descritos como femeninos, también es cierto que éstos se alternan con comportamientos clasificables como masculinos y algunos que podrían ser calificados de masculinos o femeninos. Por ejemplo, Artemio ofende a Alejandra durante su primera salida, haciendo que ella se retire bruscamente. Su reacción a este percance es beberse seis brandys, un comportamiento que puede ser leído como masculino en el contexto social planteado en el mundo ficticio del libro. Sufriendo la resaca al otro día se mete a la ducha para "llorar a gusto", una acción ambigua en términos de performance de género, ya que podría ser interpretada tanto como arrebato alcoholizado masculino o ademán melodramático femenino (68). En su afán de encarnar una masculinidad apropiada para la clase social a la que aspira, Artemio usa el dinero de su primo a su disposición para comprar un carro de lujo. Siendo que lo ha adquirido más 
que nada para impresionar a Alejandra, un día el joven la lleva a una reunión de damas de sociedad, pero se ofende cuando ella le pide que espere afuera. Volviendo resentido y medio borracho más tarde, dice a Alejandra que lo llame cuando requiera de sus servicios de chofer. Este "arranque sentimental", como lo llama Artemio, bien podría ser calificado como una reacción masculina o femenina ante la percibida ofensa, mientras el acto de transportar a la mujer en su carro es claramente un papel masculino en el contexto social descrito en la novela (129-130). Esta ambigüedad performativa, tomando en cuenta la conexión entre performance y sexualidad, apoya la lectura de Artemio como un personaje cuya orientación sexual es mejor descrita como bisexual.

Fruta verde también establece una relación entre la performatividad del género y la orientación sexual. La caracterización de Mauro explora el lugar del performance de la feminidad en la cultura gay mexicana de los setenta. Por ejemplo, relata a un amigo como su salida del clóset, en la casa de sus padres en Tabasco, fue todo un show chocante y escandaloso: "Justo a la hora del intercambio de regalos, cuando toda la familia se abrazaba en el clímax de la felicidad hogareńa, apareció en la sala con el bikini rojo de su hermana Delia, tacones altos y peluca rubia, bailando el Mambo número 8 con lúbricos meneos de cadera, al estilo de su adorada rumbera Ninón Sevilla” (95). Esta escena establece el patrón de comportamiento de Mauro para el resto de su vida — desafiante y nada tímido, echa su sexualidad en la cara de la gente con su performance lúdico de una feminidad exagerada, que usa como escudo para enfrentarse a la discriminación. Así, cuando Mauro llega al trabajo después de haber sido golpeado por unos jóvenes, explica: "Pues aquí me tienes, como la flor de la canela, con jazmines en el pelo y golpes en la cara” (183). Germán se asombra con la fuerza de Mauro para sobrellevar semejante trauma escudándose con el 
humor y le fascina el aspecto lúdico y performativo de la cultura gay.

Esta fascinación crece en cuanto se profundiza la relación entre Mauro y Germán, hasta el momento en que éste llega a adoptar algunos ademanes performativos también. Nota en su diario que tiene una "licencia para jotear" que se está atreviendo a usar con sus "hermanas" de la oficina, quienes le apodan Sor Juana por sus hábitos de estudio. "Cuando le digo 'manita' a la Chiquis o nos ponemos a hablar con la letra 'i' en las juntas de la oficina ('quí bírbiri mijir') me siento como pez en el agua" (263-264). Sin embargo, Germán no emplea esa licencia con su familia y sus amigos heterosexuales. Esta división en su comportamiento es reflejada en sus quejas sobre la falta de aceptación que percibe en los dos mundos que habita: "Preferiría tener una sola cara con bigote y rímel en las pestañas, en vez de cambiar de papel según el público que me observa" (264). Después de terminada su relación con Mauro, parece que Germán se inclina por el lado del mundo heterosexual hasta la muerte de su amigo, cuando hace el papel de viuda en el funeral: "No me molestó desempeńar ese papel durante el velorio, ni me sentí un impostor al recibir los pésames en la capilla ardiente, porque la viudez es un vacío espiritual, más que un estado civil, y yo traía el alma tan enlutada como Juana la Loca" (296). Este último performance hace pública la relación de amantes que había existido entre él y Mauro y, por ende, su orientación bisexual, reflejada a lo largo de la novela en su exploración de los aspectos performativos de la sexualidad.

Por supuesto, el vaivén performativo de un personaje no significa en sí una orientación bisexual. Adonis García, el protagonista de El vampiro de la colonia Roma, la novela de Luis Zapata, también demuestra un performance ambiguo y aunque tiene relaciones sexuales con una mujer, su orientación homosexual no es cuestionable. En el caso de Púrpura y Fruta verde, sin embargo, la lectura 
de los protagonistas como bisexuales depende no solamente de su performance de género, sino también de sus prácticas sexuales y de su atracción hacia ambos sexos. La problemática inserción de estos personajes bisexuales a sus respectivas sociedades es el punto donde entra en juego la relación irónica establecida entre las dos novelas y la tradición literaria del Bildungsroman. Es el diálogo con este género novelesco que permite leer estas obras como críticas de las identidades sexuales hegemónicas en México.

\section{Dos Bildungsromane bisexuales}

El término alemán Bildungsroman significa literalmente 'novela de formación', y se refiere a una novela en la que se narra una etapa de desarrollo moral, espiritual y social del protagonista. A finales del siglo XIX, el filósofo alemán Wilhelm Dilthey identifica la obra de Goethe, Los años de aprendizaje de Wilhelm Meister (1795), como el primer ejemplo del género. A finales del siglo XX, Marianne Hirsch propone una extensión de la definición clásica del Bildungsroman para incluir novelas decimonónicas inglesas y francesas que comparten muchos rasgos con las alemanas, pero que también reflejan las distintas sociedades de sus países de origen, como Grandes esperanzas (1861), de Dickens, y El rojo y el negro (1830), de Stendhal. La pan-europea novela de formación, como la llama Hirsch, tiene su auge en el siglo XIX y se distingue por varios rasgos, incluyendo, entre otros, el enfoque en un solo personaje y su desarrollo dentro de un orden social; la representación de los valores del orden social a través de las experiencias de dicho personaje y la visión irónica del narrador con respecto a las experiencias del protagonista (1979: 296-300). Se trata de una novela cuyo tema central es el conflicto entre el individuo y la sociedad, representado de manera irónica por un narrador situado a cierta distancia temporal o afectiva de la 
acción. Estos rasgos de la novela de formación están presentes en ambas Púrpura y Fruta verde.

Como ha observado Anadelí Bencomo, Púrpura demuestra una clara relación paródica con el género del Bildungsroman, y en particular con El rojo y el negro (2008: 85). De hecho, Artemio se compara con Julien Sorel, el protagonista de la novela de Stendhal, ya que cambia de posición social de manera vertiginosa (García Bergua, 1999: 36). Como Julien, Artemio se enfrenta con un mundo al que quiere acceder, y del cual se da cuenta paulatinamente que está lleno de falsas apariencias y traiciones. A lo largo de la novela experimenta varios desengańos relacionados con los otros personajes y el mundo al que aspira: Alejandra Ledesma es cínica y está hastiada de la sociedad; Mauro está coludido con la mafia china y con un general exiliado que quiere protagonizar un golpe de estado; su amigo Willie Fernández, empleado de una compañía en la que Mauro es accionista, resulta ser proxeneta, poeta, anarquista y policía. Artemio experimenta una decepción particularmente simbólica al descubrir que la suntuosa decoración de la casa de Mauro preparada por Freddy Santamaría no es más que un gran set de película, hecho con materiales baratos y pronto a desmoronarse: "Igual a mí todo me parecía suntuoso; ¿pues en qué escala de las cosas vivía yo, o más bien en qué escala tan pequeña, que me era imposible distinguir lo real de los disfraces? Si esto era sólo un escenario efímero, ¿qué era todo lo demás?” (119)

Tales desengaños están relatados irónicamente por el narrador, el Artemio mayor que se encuentra en Hollywood, temporal y espacialmente alejado de la acción. La actitud irónica es evidente, por ejemplo, en la narración de su primer concierto en el Palacio de Bellas Artes, donde la alta sociedad capitalina no se comporta con la elegancia esperada: "De palco a palco cundían los brindis, y de no suponer que yo ignoraba demasiadas cosas, me hubiera dicho a mí mismo que qué guarapetas se ponía la gente en los 
conciertos" (43). Como vimos arriba en los comentarios sobre el performance, esta visión irónica también se extiende a algunos comentarios relacionados con las angustias del joven Artemio sobre su orientación sexual; por ejemplo, su "doncellez masculina". Como veremos a continuación, la ambigüedad sexual señalada por tales comentarios se relaciona con la situación del personaje en la sociedad, que también es ambigua.

A diferencia de Púrpura, Fruta verde establece una relación menos directa con la novela de formación, aunque la influencia de ese género en su construcción es notable. El hecho de que Fruta verde incluya dos personajes más que podrían considerarse protagonistas (Mauro y Paula) lo aparta del Bildgunsroman clásico, aunque la identificación del personaje Germán al final de la novela hace posible la lectura de la novela como reflejo de sus propias experiencias. Como Artemio, Germán busca ingresar a un mundo superior, en este caso el de los escritores y la cultura. En el transcurso de su formación, se establece un conflicto entre el mundo del hogar, presidido por Paula y asociado con el sentido del deber, y el mundo de la oficina, presidido por Mauro y asociado con la experimentación. Germán vive el conflicto de tener un pie en cada esfera. Empieza a sentirse rechazado por el mundo del hogar, ya que los viejos amigos lo tratan como "la oveja rosa de la palomilla", pero al mismo tiempo se preocupa por pasar demasiado tiempo con Mauro, sintiéndose como "Pinocho cuando se va de pinta al país de la Jauja y la molicie lo transforma en burro" (186-187). Como vimos arriba en los comentarios sobre el performance de género, estas dos esferas son asociadas con la orientación sexual, de manera que la bisexualidad de Germán lo vuelve extranjero en ambos mundos.

La estructura narrativa de Fruta verde es más compleja que la de Púrpura, ya que incorpora varios puntos de vista a través de la inclusión del capítulo final, unos fragmentos de diarios y de cartas, algunos diálogos. Además, la mayoría de la trama es relatada en 
estilo indirecto libro por un narrador. A través de esta complejidad narrativa, es evidente el tono irónico y hasta satírico con el que se presenta el pensamiento defectuoso de los tres personajes centrales, fruto de sus prejuicios y errores. Germán, al entrar a la universidad, se vuelve marxista y no se da cuenta las contradicciones en las que cae al propugnar su versión de esa ideología, como cuando defiende a Fidel Castro a la vez que sale a favor de los derechos de los homosexuales en México (186-192). Paula, enfrascada en una abstinencia autocompasiva desde su divorcio del padre de Germán, se obsesiona con la vida sexual de los otros personajes, incluyendo a su hijo, y se preocupa de haberlo desviado regańándolo públicamente por orinarse la cama cuando nińo (204). Mauro, por su parte, parece querer que Germán se asuma como gay y que mantenga su identidad heterosexual al mismo tiempo (274-275). Así, las actitudes de Paula y Mauro, que parecen exigir una identificación tajante con la heterosexualidad u homosexualidad, refuerzan el sentimiento de alienación de Germán por su orientación bisexual.

Tanto en Púrpura como en Fruta verde, pues, se puede apreciar la influencia de ciertos rasgos de la novela de formación según Hirsch, particularmente el planteamiento de un conflicto entre el personaje principal y su sociedad. Sin embargo, hay unas diferencias importantes entre el clásico Bildungsroman, o novela de formación, y estas dos novelas que hacen posible concebirlas no como pertenecientes a la clasificación decimonónica, sino como apropiaciones posmodernas del género. De acuerdo con Umberto Eco, una de las característica esenciales de la literatura posmoderna es una relación irónica con pasadas tradiciones literarias, que permite el empleo de antiguas formas estéticas con una visión actualizada (1988: 659). ${ }^{12}$ La actitud básica epistemológica posmoderna ha

12 Por ejemplo, una novela contemporánea posmoderna puede emplear los recursos estéticos del realismo decimonónico, pero tendrá una relación irónica 
sido resumida por Jean-François Lyotard como un escepticismo hacia los grandes relatos, las ideas organizadoras de la realidad tales como el cristianismo, el positivismo o el comunismo (1984: XXIV). De acuerdo con estas interpretaciones de lo posmoderno, Púrpura y Fruta verde pueden ser leídas como textos que entablan una relación posmoderna con la novela de formación o Bildungsroman, ya que se reapropian de esa forma originaria del siglo diecinueve para ironizarla y cuestionar algunos valores actuales —en este caso, la noción binaria de la orientación sexual.

Según Hirsch, en la novela de formación el tema del desarrollo del yo dentro de la sociedad se explaya en el planteamiento de una adaptación del protagonista a su entorno social (que puede ser aceptado o rechazado), y se cierra al final de la novela cuando el personaje proporciona una clara evaluación de su lugar en la sociedad (298). Hirsch también argumenta que la novela de formación tiene una clara función didáctica —se supone que el lector aprende algo a través de la lectura del proceso de aprendizaje del protagonista (300). En Púrpura y Fruta verde se plantean múltiples adaptaciones sociales, no queda clara la evaluación del protagonista de su lugar social, y la función didáctica es reemplazada por una función de cuestionamiento. Así, la afirmación didáctica moderna del Bildungsroman o novela de formación clásica es supeditada a un cuestionamiento posmoderno que, en el caso de estas dos novelas, puede ser leído como una crítica de las identidades sexuales basadas en una noción binaria de la orientación sexual (heterosexual / homosexual).

Para el final de Púrpura, habiendo descartado la opción de escaparse a Campeche con Alejandra, las posibilidades de Artemio se han reducido básicamente a dos: volver a su pueblo o quedarse en México trabajando en el cine con Freddy Santamaría y recibiendo

(conocedora, no ingenua) con el episteme que subyacía el desarrollo del realismo en el periodo de su primer auge. 
dinero de Mauro. La meta original de entrar a la alta sociedad ya no le interesa después de sus desengaños, y está resuelto a "emprender una nueva vida por mis propios medios" (170). De las alternativas enumeradas arriba, que podrían considerarse posibles adaptaciones sociales, Artemio escoge la última, pero sólo inicialmente. Al fin y al cabo, decide cortar con Mauro porque no quiere estar envuelto en sus negocios turbios y deja la carrera de actor por la de guionista. En las últimas páginas de las novelas, descubrimos que Artemio se ha mudado a Hollywood con sus amigos Ramón y Lola. En este momento el protagonista parece efectuar una evaluación de su lugar en la sociedad que, sin embargo, es muy ambigua. Cuenta haber visto en un periódico una fotografía de Alejandra Ledesma en París acompañada de un joven escritor francés, hecho que le inspira unas cavilaciones:

La idea de que ese joven pude haber sido yo, quizá, me persigue desde entonces en mis insomnios, mientras miro por la ventana las estrellas de estas noches calientes de California, y Ramón y Lola duermen como nińos en el king size.

Lo bueno es que sufro pocos insomnios (171).

Estas líneas cierran la novela con suma ambigüedad. ¿Artemio está aliviado por haberse escapado del fin del joven escritor francés o lo añora? ¿ O las dos cosas?

La inclusión de Ramón y Lola en la escena es a la vez ambigua y sugerente. Aunque finalmente el asunto no se aclara, se puede inferir que la cama es compartida por los tres, lo cual podría indicar, como argumenté arriba, la bisexualidad de Artemio (y de Ramón). Sin embargo, no se puede hablar de un planteamiento tajante de la orientación sexual de Artemio, sino más bien una serie de eventos e insinuaciones cuyo resultado final es la no-adopción de ninguna identidad sexual. El rechazo de la relación con Alejandra puede interpretarse como el rechazo de una identidad heterosexual dudosa: 
"Me había pasado por la cabeza la idea de ser discreto, frecuentar a las mujeres y hacer como muchos hombres, que se daban a veces aquel género de gustos [la homosexualidad] sin darse por aludidos [...]" (123). La otra opción presente en la novela es la identidad básicamente homosexual pero más o menos encubierta de Mauro y Freddy. Sin embargo, no hay indicios de que Artemio escoge tal identidad tampoco. Quedamos, pues, con la insinuación de una tercer vía que correspondería con la orientación bisexual de Artemio.

El final de Fruta verde, que viene en forma de una coda intitulada "Ofrenda", actualiza la historia de Germán, relatando como después de terminar con Mauro se casa con una mujer, tiene una hija, se divorcia y sobrevive a su madre y a su ex-amante. Como vimos arriba, el conflicto sujeto / sociedad en esta novela está claramente ligado a la orientación sexual y la identidad, y a Germán se le plantean esencialmente dos posibles adaptaciones sociales: asumirse como gay o como heterosexual. Por lo que nos cuenta sobre su vida, parecería haber optado por la segunda opción durante muchos años. Sin embargo, como el único ex-amante de Mauro que no lo había abandonado, a Germán le toca el papel de viuda en el funeral, una participación relatada en términos de un performance de feminidad, como se analizó arriba. Este reconocimiento público de su pasada relación con Mauro puede leerse como una salida del clóset de Germán como bisexual. Sin embargo, el protagonista no cuenta nada sobre los efectos sociales que podría haber tenido el acto de asumir una sexualidad disidente públicamente. El proceso de duelo y de creación del manuscrito de la novela parece darle a Germán un sentido de paz interior, que es representado plásticamente por un sueño en el que los fantasmas de Paula y Mauro se reconcilian sobre un altar de día de los muertos. Pero no se describe el efecto social de la salida del clóset de Germán ni se plantea ninguna evaluación de su lugar en la sociedad. Como 
en Púrpura, en esta novela la ambigüedad en torno a la evaluación del protagonista de su lugar social redunda en un texto en el que cualquier función didáctica es supeditada a una función de cuestionamiento. Y como en Púrpura, tal cuestión puede leerse como una crítica de las identidades sexuales basadas en una concepción binaria de la orientación sexual.

\section{Conclusiones}

$\mathrm{Al}$ argumentar que estas novelas pueden ser leídas como críticas de las identidades sexuales, cabe preguntar por qué conviene entonces rotular a los personajes como bisexuales, en vez de emplear otra terminología. Por ejemplo, una posible alternativa para hablar de la sexualidad de los protagonistas de estas obras sería queer, ${ }^{13}$ una palabra inglesa peyorativa recuperada por ciertas comunidades de disidencia sexual en Estados Unidos para señalar toda sexualidad que no cabe dentro de los constreńimientos de las normas sociales de sexo y género ("queer", 2006). El movimiento político que enarbola la recuperación de este término está relacionado con una corriente de pensamiento conocida como la teoría queer, de la que Judith Butler, citada antes, es un ejemplo. Tanto el uso político del término queer como la teoría académica asociada encierran un profundo cuestionamiento de la noción de la identidad en sí, y por lo tanto podrían muy bien aplicarse a la descripción de los personajes de Púrpura y Fruta verde. Sin embargo, el uso de queer para señalar una orientación sexual (o falta de la misma) puede ser más deconstructivo que productivo. Aunque la noción de una sexualidad queer podría ayudar a desafiar las restricciones de las sexualidades normativas, su erosión de la identidad puede socavar la fuerza política, social y retórica de las identidades disidentes como la bi-

13 "Raro", "extraño". 
sexual, la gay y la lesbiana. ${ }^{14}$ Así, el uso del término queer para hablar de sexualidades disidentes puede contribuir al allanamiento de la diferencias entre tales sexualidades, algo que en última instancia podría distraer de los diferentes tipos de marginación social que viven personas con diferentes orientaciones sexuales. ${ }^{15}$ Aunque las representaciones literarias de la disidencia sexual no siempre están directamente relacionadas con las nociones de identidad o de reivindicación política, siguen siendo importantes en cuanto expresiones artísticas de sexualidades disidentes, que pueden funcionar tanto como seńalamientos de diferencias socialmente marginadas como planteamientos de cuestiones culturales y sociales relacionadas con la sexualidad.

Si descartamos queer como una posibilidad para categorizar los protagonistas de las dos novelas analizadas aquí, sin embargo, cabe preguntar por qué hace falta rotularlos con cualquier orientación sexual, si los personajes no enuncian ninguna y si las novelas no parecen seńalar una afirmación sino un cuestionamiento de la identidad sexual. Una preocupación semejante fue expresada sobre Púrpura por José Ricardo Chaves, para quien hablar de Artemio como bisexual traicionaría "[...] el espíritu de la obra, pues ésta no pretende definir taxonomía libidinales sino tan sólo explorar los meandros de eros, sin nombres, sin etiquetas provenientes de ideologías sexuales, a partir del laberinto de Artemio" (1999: 14). Sin embargo, este acercamiento no es satisfactorio, ya que nos lleva al mismo problema que encierra el empleo de lo queer. Al dejar de señalar la diferencia de la sexualidad de los personajes de estas obras borramos también la transgresión y disidencia que encierran las sexualidades no-normativas, las cuales son sujetas a la marginalización en la sociedad en que se produjeron las novelas. Por

${ }^{14}$ Cfr. Edwards, 1998 y Green, 2002.

15 Se puede pensar, por ejemplo, en los distintos tipos de discriminación que enfrentan los hombres gays y las mujeres lesbianas. 
eso argumento que es importante reconocer la representación de una sexualidad disidente en Púrpura y Fruta verde, que es mejor descrita como bisexualidad masculina. La categoría de literatura de disidencia sexual mexicana que planteo arriba es una definición sumamente abierta, porque la disidencia sexual no abarca una sola sexualidad, sino varias. La inclusión de la literatura que retrata la bisexualidad masculina dentro de esta tradición es un paso importante a la construcción de un canon literario de disidencia sexual pluralista e inclusivo.

\section{Bibliografía}

Beemyn, Brett Genny, 2004, "Bisexuality”, en glbtq: An Encyclopedia of Gay, Lesbian, Bisexual, Transgender and Queer Culture, en: www.glbtq.com/social-sciences/bisex.html.

Bencomo, Anadeli, 2008, "La imaginadora: el arte narrativo de Ana García Bergua”, Explicación de Textos Literarios, núms. 1-2, vol. 36, pp. 78-90.

Blanco, José Joaquín, 1981, “Ojos que da pánico soñar”, en Función de medianoche: Ensayos de literatura cotidiana, México, Era, pp. 183-190.

Butler, Judith, 1988, "Performative Acts and Gender Constitution: An Essay in Phenomenology and Feminist Theory", Theatre Journal, núm. 4, vol. 40, diciembre, pp. 519-531.

Cázares H., Laura, 2001, "Del rancho a la capital: Púrpura de Ana García Bergua”, en Ana Rosa Domenella (coord.), Territorio de leonas: Cartografía de narradoras mexicanas en los noventa, México, Universidad Autónoma Metropolitana / Casa Juan Pablos, pp. 339-353.

Chaves, José Ricardo, 1999, “Púrpura: el color del deseo”, La Jornada, 3 de octubre, p. 14. 
Domínguez Michael, Christopher, 1999, "De Sodoma a Gomorra” (Reseña de Púrpura de Ana García Bergua), Letras Libres, núm. 8, agosto, pp. 91-92.

Edwards, Tim, 1998, "Queer Fears: Against the Cultural Turn", Sexualities, núm. 1, vol. 1, febrero, pp. 471-484.

Eco, Umberto, 1988, "Lo posmoderno, la ironía, lo ameno", en Apostillas a El nombre de la rosa, Barcelona, Lumen, pp. 658664.

Garber, Marjorie, 1995, Vice Versa: Bisexuality and the Eroticism of Everyday Life, Nueva York, Simon \& Schuster.

García Bergua, Ana, 1999, Púrpura, México, Era.

García Hernández, Arturo, 2006, "Fruta verde, novela de aprendizaje sobre amor cínico: Enrique Serna”, La Jornada, 11 de diciembre, en: http://www.jornada.unam.mx/2006/12/11/index.php? section $=$ cultura\&article $=\mathrm{a} 10 \mathrm{n} 1 \mathrm{cu}$

Gil, Eve, 2007, "Electricidad enamorada”, en La nueva ciudad de las damas: Feminismo y literatura, noviembre, en: http://otratrenza.blogspot.com/2007/11/electricidad-enamorada.html.

Green, Adam, 2002, "Gay But Not Queer: Toward a Post-Queer Study of Sexuality", Theory and Society, núm. 4, vol. 31, pp. 21-45.

Hirsch, Marianne, 1979, “The Novel of Formation as Genre: Between Great Expectations and Lost Illusions", Genre, núm. 12, pp. 293-311.

"Irreverencia y bisexualidad en Fruta Verde, de Enrique Serna", en anodis.com, México, 3 de noviembre, en http://anodis.com/ nota/8017.asp.

Irwin, Robert McKee, 2000, "La Pedo Embotellado: Sexual Roles and Play in Salvador Novo's La estatua de sal', Studies in the Literary Imagination, núm. 1, vol. 33, primavera, pp. 125-32. 
Lyotard, Jean François, 1984, The Postmodern Condition: A Report on Knowledge, Geoff Bennington y Brian Massumi (trads.), Minneapolis, Univeristy of Minnesota Press.

Monsiváis, Carlos, 1995, "Ortodoxia y heterodoxia en las alcobas”, Debate Feminista, núm.11, vol. 6, pp. 183-210.

Palaversich, Diana, 1999-2000, "El femenino monstruoso y la crisis del género en La hermana secreta de Angélica Maria", Antípodas, núms. 11-12, pp. 233-248.

"queer", 2006, en glbtq: An Encyclopedia of Gay, Lesbian, Bisexual,Transgender, and Queer Culture, en: http://www.glbtq. com/glossary.php?id=17

Salinas Hernández, Héctor Manuel, 2010, Políticas de disidencia sexual en América Latina. Sujetos sociales, gobierno y mercado en México, Bogotá y Buenos Aires, México, Eón.

Serna, Enrique, 2006, Fruta verde, México, Planeta.

Sifuentes-Jáuregui, Ben, 2002, Transvestism, Masculinity, and Latin American Literature: Genders Share Flesh, Nueva York, Palgrave.

Thornton, Niamh, 2010a, "Ana García Bergua’s Púrpura: Gay Narrative and the Boom Femenino in Mexico", en The Boom Femenino in Mexico: Reading Contemporary Women's Writing, Newcastle upon Tyne, Cambridge Scholars, pp. 217-240.

, 2010b, "Being Fruity in the Big City: Re-membering the Past in Enrique Serna's Fruta verde", Ulster Institutional Repository, 17 de febrero, en: http://eprints.ulster.ac.uk/11916/ 